\title{
HUBUNGAN PENERAPAN RAWAT GABUNG DAN KELOMPOK PENDUKUNG ASI (KP-ASI) DENGAN CAKUPAN ASI EKSKLUSIF DI KABUPATEN PANGKEP
}

The Correlation Of The Implementation Of Combination And Assistant Supporting Groups With Coverage Exclusive At Pangkep Distrists

Nasriani

Prodi D III Keperawatan Fakultas Kedokteran Dan IImu Kesehatan Unismuh Makassar Email : nasriani@unismuh.ac.id/085342533598

\begin{abstract}
The Indonesian government has made efforts to increase exclusive breastfeeding in various ways. The issuance of laws and regulations regarding exclusive breastfeeding has also been carried out, but the implementation has not been following the Indonesian National Standard (SNI). This study aims to analyze the relationship between the application of admission care and the formation of a support group (KP) Asi with exclusive breastfeeding coverage in Pangkep Regency. This study was an observational analytic study with cross-sectional study design. The population in this study was the Public Health Center who were in all Pangkep District health centres, as many as 23 Public Health Center. Sampling from the study population was carried out by means of purposive sampling, namely 22 Public Health Center with inpatients in Pangkep district. Data collection was carried out by looking at the exclusive ASI report of the Pangkep District Health Office, distribution of questionnaires, interviews and then processed using the SPSS program with the chi-square test. Data analysis techniques using univariate, bivariate and multivariate tests with the forward step method (conditional). The results showed that $(p<0.05)$ which means $\mathrm{HO}$ was rejected. Thus the application of merger care is related to exclusive ASI coverage Keywords: Exclusive ASI, Application of Combined Care and Formation of Breast Milk Support Groups
\end{abstract}

\section{ABSTRAK}

Pemerintah Indonesia telah melakukan upaya peningkatan pemberian ASI eksklusif dengan berbagai cara. Menerbitkan peraturan dan perundang- undangan mengenai pemberian ASI eksklusif pun sudah dilakukan, namun pelaksanaannya belum sesuai dengan Standar nasional Indonesia (SNI). Penelitian ini bertujuan untuk menganalisa hubungan penerapan rawat gabung dan pembentukan kelompok pendukung (KP) Asi Dengan Cakupan ASI Eksklusif Di Kabupaten Pangkep. Penelitian ini adalah observasional analitik dengan rancangn cross sectional study. Populasi dalam penelitian ini adalah seluruh puskemas Kabupaten Pangkep yaitu sebanyak 23 puskesmas. Penarikan sampel dari populasi penelitian dilakukan dengan cara purposive sampling yaitu puskesmas yang memiliki rawat inap di kabupaten pangkep sebanyak 22 puskesmas. Pengumpulan data dilakukan dengan cara melihat laporan ASI Eksklusif Dinas Kesehatan kabupaten Pangkep, pembagian kuesioner, wawancara kemudian diolah dengan menggunakan program SPSS dengan uji chi square. Teknik analisa data dengan menggunakan uji univariat, bivariat dan multivariate dengan metode forward stepwice (conditional). Hasil penelitian menunjukkan bahwa $(p<0,05)$ yang berarti $\mathrm{H}_{0}$ ditolak. Dengan demikian penerapan rawat gabung berhubungan dengan cakupan ASi eksklusif.

\section{Kata kunci : ASI Eksklusif, Penerapan Rawat Gabung dan Pembentukan Kelompok Pendukung (KP) ASI}

\section{PENDAHULUAN}

Menyusui merupakan salah satu aspek yang penting dilakukan oleh seorang lbu untuk menjaga kelangsungan hidup bayi guna mencapai tumbuh kembang bayilanak yang optimal. Selain itu, menyusui juga bertujuan untuk menjaga kesehatan ibu setelah bersalin. ASI Ekslusif diberikan sejak bayi baru lahir hingga bayi usia 6 bulan. Setelah 6 bulan, pemberian ASI di lanjutkan sampai anak berusia dua tahun. Tetapi, selain anak di beri ASI, anak juga di beri makanan tambahan yang cukup, baik dalam jumlah maupun mutunya yang di sebut Makanan Pendamping ASI (MP-ASI), makanan ini bisa dalam bentuk makanan lunak/padat
Kementrian kesehatan telah membuat sebuah kebijakan Nasional terkait dengan penguatan pemberian ASI Eksklusif selama enam bulan yang dituangkan dalam SK Menteri Kesehatan No.450/Menkes/SK/IV/2004. Kebijakan Nasional ini belum mencapai target di karenakan masih banyak masyarakat yang beranggapan bahwa urusan menyusui adalah urusan perempuan. Dalam rangka mencapai tujuan dari Kebijakan Nasional tersebut, maka di bentuklah salah satu kelompok kerja yang diberi nama KP-ASI Eksklusif. Kelompok ini terdiri dari Ibu-lbu yang sementara hamil dan yang mempunyai anak usia kurang dari 2 (dua) tahun. Dalam menjalankan program, kelompok tersebut di bimbing oleh motivator yang bertugas untuk 
membimbing dan memotivasi lbu-lbu sehigga lbu-lbu merasa di hargai, dicintai, diperhatikan serta didukung. Dengan munculnya energi positif di dalam ibu-ibu tersebut akan meningkatkan produksi hormon oksitosin yang bertujuab untuk melancarkan produksi ASI. (Syurandari, 2013)

Setelah ibu melahirkan, maka lbu dan bayi tidak dipisahkan, akan tetapi di rawat secara bersamasama dalam satu ruangan selama 24 jam yang disebut dengan Rawat Gabung. Rawat Gabung bertujuan untuk membantu dalam proses mempermudah pemberian ASI dari Ibu kepada bayi. Sebagaimana kita ketahui, bahwa dalam tubuh seorang Ibu yang sementara menyusui mempunyai hormon Oksitosin. Hormon oksitosin mempunyai pengaruh yang besar kepada emosi lbu. Dalam kondisi, Ibu sedang mendekap atau menggendong bayinya, maka hormon oksitosin akan meningkat yang nantinya akan merangsang dan mempercepat pengeluaran ASI, sehingga ibu termotivasi untuk terus menyusui bayinya.

Masyarakat yang akan melakukan pemeriksakan kesehatan dan pengobatan, akan lebih banyak mendatangi atau menggunakan fasilitas Puskesmas, termasuk pemeriksaan kehamilan dan persalinan. Data persalinan di seluruh Puskesmas Kabupaten Pangkep tahun 2015 sebanyak $5.462(82,09 \%)$ ibu sedangkan yang bersalin di RSUD Pangkep sebanyak $1.192(17,91 \%)$ ibu. (Dinkes Kabupaten Pangkep, 2016).

Persentase pemberian ASI eksklusif pada bayi umur 0-6 bulan di wilayah Puskesmas Kabupaten Pangkep yakni pada tahun 2011 sebesar 41.28\%, mengalami peningkatan sebanyak $57.79 \%$ pada tahun 2012, tahun 2013 juga mengalami peningkatan menjadi $(68,10 \%)$ dan mengalami penurunan di tahun 2014 sebanyak 64,4\% dan meningkat kembali pada tahun 2015 menjadi $67,71 \%$. Melihat data di atas, pemberian ASI Eksklusif di Puskesmas Kabupaten Pangkep telah mengalami peningkatan, tetapi belum memenuhi standar nasional yang ditetapkan yaitu sebesar $80 \%$

ASI sangat penting bagi bayi namun tidak semua ibu memberikan ASI eksklusif. Pemerintah mencanangkan beberapa program terkait ASI eksklusif, namun hal tersebut belum berhasil karena cakupan ASI Eksklusif belum sesuai standar nasional Indonesia (SNI) yakni $\geq 80 \%$. Maka perlu dilakukan penelitian untuk mengetahui hubungan penerapan rawat gabung dan pembentukan Kelompok Pendukung (KP) ASI dengan cakupan ASI eksklusif di kabupaten pangkep.

\section{METODE}

\section{Desain, Tempat dan Waktu}

Penelitian ini menggunakan metode observasional dengan desain cross sectional. Penelitian dilakukan di seluruh Puskesmas Kabupaten Pangkep pada bulan Juli sampai Agustus 2016.

\section{Jumlah dan cara pengambilan subjek}

Populasi dalam penelitian ini adalah semua puskemas Kabupaten Pangkep yaitu sebanyak 23 puskesmas. Penarikan sampel dalam penelitian ini dilakukan dengan cara purposive sampling yaitu puskesmas yang memiliki rawat inap di kabupaten pangkep sebanyak 22 puskesmas.

\section{HASIL}

Analisis Univariat

Grafik 1. Persentase cakupaan ASI Eksklusif di seluruh puskesmas Kabupaten Pangkep

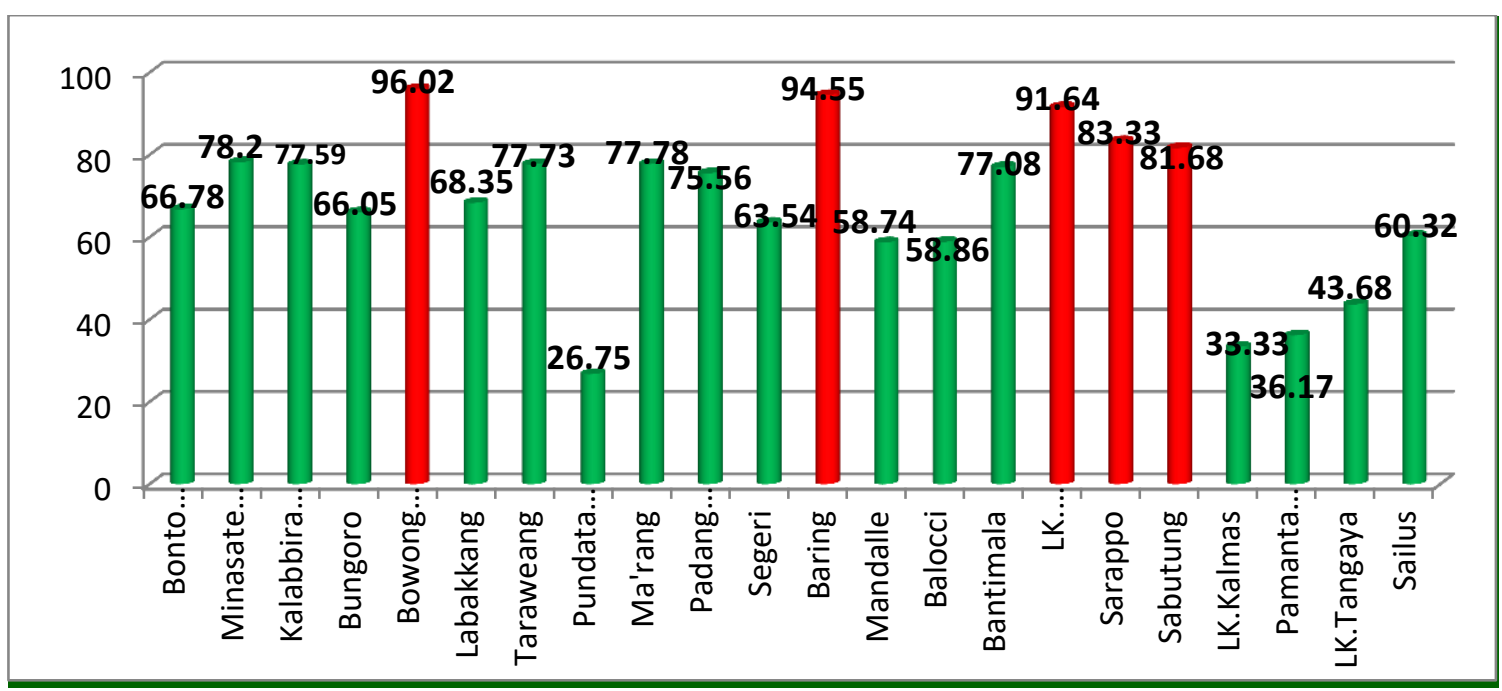

Sumber : Data Sekunder, 2015 
Grafik 1 menunjukkan bahwa persentase Cakupan ASI Eksklusif masing-masing puskesmas yang memiliki rawat inap di Kabupaten Pangkep tahun 2015, yaitu : Bonto Perak (66,78\%), Minasate'ne (78,20\%), Kalabbirang (77,59\%), Bungoro (66,05\%), Kota pangkajene $(78,49 \%)$, Bowong Cinde $(96,02 \%)$, Labakkang (68,35\%), Taraweang $(77,73 \%)$, Pundata
Baji (26.75\%), Ma'rang (77,78\%), Padang Lampe $(75,56 \%)$, Segeri $(63,54 \%)$, Baring $(94,55 \%)$, Mandalle $(58,74 \%)$, Balocci $(58,86 \%)$, Bantimala $(77,08 \%)$, LK. Tupabbiring (91.64\%), Sarappo (83,33\%), Sabutung (81.68\%), LK Kalmas $(33,33 \%)$, Pamantauang $(36,17 \%)$, LK Tangaya $(43,68 \%)$, Sailus $(60,32 \%)$.

Tabel 1. Distribusi frekuensi puskesmas berdasarkan Penerapan Rawat Gabung dan Pembentukan KP-ASI di kabupaten pangkep

\begin{tabular}{|c|c|c|}
\hline Variabel & $\mathrm{n}$ & $\%$ \\
\hline \multicolumn{3}{|l|}{ Penerapan Rawat Gabung } \\
\hline Ya & 10 & 45,45 \\
\hline Tidak & 12 & 54,55 \\
\hline Jumlah & 22 & 100 \\
\hline \multicolumn{3}{|l|}{ Pembentukan KP-ASI } \\
\hline Ya & 21 & 95,45 \\
\hline Tidak & 1 & 4,54 \\
\hline Jumlah & 22 & 100 \\
\hline
\end{tabular}

Sumber : Data Primer 2016

Tabel 1 menunjukkan bahwa Puskesmas yang tidak melaksanakan penerapan rawat gabung sebanyak 12 Puskesmas (54.5\%) sedangkan yang melaksanakan penerapan rawat gabung sebanyak 10Puskesmas (45.5\%). Sedangkan variable pelatihan petugas menunjukkan bahwa Puskesmas yang tidak melaksanakan pembentukan KP-ASI sebanyak 1 Puskesmas (4,5\%), sedangkan yang melaksanakan sebanyak 21 Puskesmas $(95,5 \%)$.

\section{Analisis Bivariat}

Tabel 2. Analisis Bivariat Penerapan Rawat Gabung dan Pembentukan KP-ASI Dengan Cakupan ASI Eksklusif Di Kabupaten Pangkep

\begin{tabular}{|c|c|c|c|c|c|c|c|}
\hline \multirow{3}{*}{ Variabel } & \multicolumn{4}{|c|}{ Cakupan ASI Eksklusif } & \multicolumn{2}{|c|}{ Jumlah } & \multirow[t]{3}{*}{$\mathbf{P}$} \\
\hline & \multicolumn{2}{|c|}{ Sesuai SNI } & \multicolumn{2}{|c|}{ Tidak Sesuai SNI } & \multirow[b]{2}{*}{$\mathrm{n}$} & \multirow[b]{2}{*}{$\%$} & \\
\hline & $\mathrm{n}$ & $\%$ & $\mathrm{n}$ & $\%$ & & & \\
\hline Penerapan Rawat Gabung & & & & & & & 0,010 \\
\hline Ya & 5 & 50,0 & 5 & 50,0 & 10 & 100,0 & \\
\hline Tidak & 0 & 0,0 & 12 & 100,0 & 12 & 100,0 & \\
\hline Jumlah & 5 & 22,7 & 17 & 77,3 & 22 & 100,0 & \\
\hline \multicolumn{8}{|l|}{ Pembentukan KP-ASI } \\
\hline Ya & 5 & 23,8 & 16 & 76,2 & 21 & 100,0 & 1,000 \\
\hline Tidak & 0 & 0 & 1 & 100,0 & 1 & 100,0 & \\
\hline Jumlah & 5 & 22,7 & 17 & 77,3 & 22 & 100,0 & \\
\hline
\end{tabular}

Sumber : Data Primer 2016 
Tabel 2 menunjukkan variable penerapan rawat gabung dengan pembentukan KP-ASI. penerapan rawat gabung dikategorikan menjadi dua yaitu melaksanakan dan tidak melaksanakan. Hasil penelitian diperoleh nilai $p=0,010(p<0,05)$ berarti Ho ditolak. Hal ini menunjukkan bahwa terdapat hubungan pelaksanaan rawat gabung dengan

\section{PEMBAHASAN}

Dari hasil penelitian ini didapatkan adanya hubungan antara penerapan rawat gabung dengan cakupan ASI eksklusif. Penerapan rawat gabung memiliki peranan yang sangat penting untuk meningkatkan dan mengembangkan keterampilan agar dapat memberikan dukungan terhadap menyusui. Penelitian ini sama dengan penelitian yang dilaksanakan oleh Wang dan Kim (2009), menemukan bahwa ibu yang melakukan rawat gabung dengan bayinya dapat meningkatkan angka menyusui dan meningkatkan kepercayaan diri untuk tetap menyusui bayinya. Lalu bagaimana dengan ibu yang telah melakukan rawat gabung tapi tetap tidak memberikan ASI Eksklusif. Banyak faktor yang mempengaruhi diantaranya pengetahuan, sikap, kepercayaan, tradisi/nilai-nilai budaya serta dukungan suami dan keluarga.

Puskesmas yang tidak melakukan rawat gabung karena puskesmas tersebut mempunyai ruangan khusus untuk bayi, selain itu adanya kasus dimana anak tidak dapat dirawat bersama ibu karena kondisi ibunya yang drop pasca melahirkan. Karena adanya hubungan berarti rawat gabung diperlukan dalam peningkatan cakupan ASI Eksklusif. Malalui program Rawat Gabung, bayi dapat disusui oleh ibunya kapan saja dibutuhkan. Selain itu, Ibu dapat melihat, memperhatikan dan mempelajari bagamana cara petugas melakukan perawatan bayi yang benar, sehingga selama di rawat di fasilitas kesehatan, ibu dapat mengetahui dan mempunyai pengalaman dalam melakukan perawatan pada bayinya. dan ketika pulang, Ibu sudah mendapatkan bekal keterampilan dalam merawat bayinya sendiri. Dalam pelaksanaan program Rawat Gabung, keluarga dapat dilibatkan secara aktif termasuk suami atau Bapak bayi tersebut. Keberadaan keluarga sangat mendukung dan membantu lbu dalam menyusui dan merawat bayinya

Hasil penelitian ini, menunjukkan tidak ada hubungan antara pembentukan KP-ASI dengan cakupan ASI eksklusif. KP-ASI adalah kegiatan yang dilakukan untuk meningkatkan cakupan ASI Eksklusif secara efektif. KP-ASI adalah kelompok yang terdiri ibu-ibu hamil dan ibu yang memiliki anak usia kurang dari 2 tahun. Kelompok ini mengadakan pertemuan secara rutin setiap bulan, selain pertemuan rutin, kelompok ini juga melakukan kunjungan rumah untuk berdiskusi, saling bertukar pengalaman, memberi dukungan, serta melakukan penyulusahan terkait cakupan ASI Eksklusif. Variabel pembentukan KPASI dikategorikan menjadi 2 yaitu melaksanakan dan tidak melaksanakan. Hasil penelitian diperoleh nilai $p=1,000 \quad(p>0,05)$ berarti Ho diterima. Hal ini menunjukkan bahwa tidak ada hubungan pelaksanaan pembentukan KP-ASI dengan cakupan ASI $\quad$ Eksklusif

kesehatan ibu dan anak khususnya seputar kehamilan, menyusui dan gizi Bumil dan anak. Kelompok ini juga memberikan nasehat tentang cara mengatasi permasalahan yang ditemui pada waktu menyusui, yang dipandu/difasiltasi olehh motivator

Puskesmas yang tidak melakukan pembentukan KP-ASI disebabkan terbatasnya waktu dan tenaga untuk pelaksanaan kegiatan-kegiatan KP-ASI. Sangat penting dalam masyarakat untuk membentuk sebuah KP-ASI. KP-ASI selain beranggotakan ibuibu hamil dan menyusui, kelompok ini juga melibatkan para suami, tokoh masyarakat dan tokoh agama. Tujuan dari melibatkan para tokoh agama dan tokoh Masyarakat adalah dikarenakan mereka adalah tokoh yang dihormati sehingga dengan kesadaran, perhatian dan kepedulian para tokoh tersebut diharapkan mereka mampu menjadikan kegiatan menyusui sebagai sebuah gerakan atau budaya dan merupakan suatu bentuk amal ibadah. Dengan menumbuhkan menyusui sebagai suatu gerakan, budaya, serta salah satu bentuk ibadah dalam masyarakat maka akan muncul upaya untuk terus menciptakan kondisi yang kondusif bagi berlangsungnya kegiatan menyusui.

Penelitian yang dilakukan oleh Susilo, J dkk (2012), yang menemukan bahwa KP-ASI terbukti dapat meningkatkan cakupan ASI Eksklusif karena suasana saling memberi dukungan lebih mudah terbangun dalam kelompok teman sebaya yang mempunyai pengalaman dan situasi lingkungan yang sama.

\section{KESIMPULAN}

Penerapan rawat gabung merupakan faktor yang saling berhubungan dengan cakupan ASI eksklusif, sedangkan pembentukan kelompok pendukung (KP) ASI merupakan faktor yang tidak berhubungan dengan cakupan ASI eksklusif. Penerapan rawat gabung akan meningkatkan ikatan emosional/batin antara ibu dan bayinya. Semakin banyak waktu ibu bersama bayinya, maka semakin cepat lbu dan bayinya saling mengenal. Ibu akan selalu siap memberikan respon. Rawat gabung juga dapat menurunkan hormon yang memicu stres pada ibu dan bayi.

\section{SARAN}

Diharapkan program pembentukan KP-ASI dan rawat gabung di masing-masing wilayah dengan dibantu oleh bidan desa dan kader kesehatan 
setempat sehingga dapat memberikan dukungan pada ibu yang sementara hamil dan ibu yang mempunyai anak usia kurang dari dua tahun supaya dapat memberikan ASI secara eksklusif.
UCAPAN TERIMA KASIH

Dekan Fakultas Kedokteran dan IImu Kesehatan Unismuh Makassar, Prodi D III Keperawatan Fakultas Kedokteran dan IImu Kesehatan Unismuh Makassar, Kepala Puskesmas dan staf di seluruh puskesmas kabupaten pangkep.

\section{DAFTAR PUSTAKA}

Astuti I. (2013). Determinan Pemberian Asi Eksklusif Pada Ibu Menyusui. Jurnal Health Quality, Vol. 4 No. 1 Hal. 1 76.

Brown A. \& Arnot B. (2014). Breastfeeding Duration And Early Parenting Behaviour: The Importance Of An InfantLed, Responsive Style. Plos One 9.

Dinkes Kabupaten Pangkep. (2015). Profil Kesehatan Dinas Kesehatan kabupaten Pangkep. Diakses Tanggal 10 Maret 2016. Available from : https://diskes. wordpress.com/

Dinas Kesehatan Sulsel. (2013). Profil Kesehatan Provinsi Sul-Sel. Diakses Tanggal 10 Maret 2016. Available from : https://www.dinkes.sulselprov.go.id/Profil Kesehatan SulSel

Dwi Helynarti Syurandari. (2013). Pemberdayaan masyarakat kelompok pendukunh KP-ASI. Diakses Pada Tanggal 10 maret 2016. Available from https:// www.academia.edu/

Gage H.P.W. et al (2012). Influences On Infant Feeding Decisions Of First-Time Mothers In Five European Countries. European Journal Of Clinical Nutrition 66, 914-919, 6, 914-919.

Helda. (2009). Kebijakan Peningkatan Pemberian ASI Eksklusif. Jurnal Kesehatan Masyarakat Nasional Vol. 3, No. 5 , April 2009

Henderawaty R. dkk. (2014) Analisis Implementasi Kebijakan Pemberian Air Susu Ibu Eksklusif Bagi Ibu Bekerja di Provinsi Kalimantan Selatan. Jurnal Manajemen Kesehatan Indonesia Volume 2

Josefa K.G. (2011). Faktor-faktor yang Mempengaruhi Perilaku Pemberian ASI Eksklusif pada Ibu (Studi Kasus di Wilayah Kerja Puskesmas Manyaran, Kecamatan Semarang Barat). Skripsi. Semarang: Fakultas Kedokteran UNDIP.

Marcel Y, Chalachala J.L., Labbok M. \& Behets F. (2013). Infant Feeding Practices And Determinants Of Poor Breastfeeding Behavior In Kinshasa, Democratic Republic Of Congo: A Descriptive Study. International Breastfeeding Journal

Mgongo M., Mosha M. V., Uriyo J.G., Msuya S.E. \& Stray-Pedersen B. (2013). Prevalence And Predictors Of Exclusive Breastfeeding Among Women In Kilimanjaro Region, Northern Tanzania: A Population Based Cross-Sectional Study. Int Breastfeed J, 8, 12.

Prasetyono D.S. (2012). ASI Eksklusif. Jakarta, Rineka Cipta

Reddin E., Pincombe J., \& Darbyshire P. (2007). Passive resistance: early experiences of midwifery students/graduates and the Baby Friendly Health Initiative 10 steps to successful breastfeeding. Women Birth, 20(2):71-6

Seid A.M., Yesuf M.E., \& Koye D.N. (2013). Prevalence Of Exclusive Breastfeeding Practices And Associated Factors Among Mothers In Bahir Dar City, Northwest Ethiopia: A Community Based Cross-Sectional Study. Int Breastfeed J, 8, 14.

Setegn T. et al. (2012). Factors Associated With Exclusive Breastfeeding Practices Among Mothers In Goba District, South East Ethiopia: A Cross-Sectional Study. International Breastfeeding Journal Vol. 7. 
Tengku A.T., Wan A.M., Zaharah S., Rohana A.J., \& Nik N.M. (2012). Perceptions And Practice Of Exclusive Breastfeeding Among Malay Women In Kelantan, Malaysia: A Qualitative Approach. Malays J Nutr, 18, 2225.

Uchenna O. (2012). Problems Encountered By Breastfeeding Mothers In Their Practice Of Exclusive Breast Feeding In Tertiary Hospitals In Enugu State, South-East Nigeria. International Journal Of Nutrition And Metabolism Vol 4, 107-113. 